\title{
Konsep Tanggung Jawab Suami dalam Mendidik Istri Perspektif Hadis Nabi Muhammad SAW Pada Kitab Kutub al-Tis'ah
}

\author{
Nurhadi \\ Sekolah Tinggi Agama Islam (STAI) Al-Azhar Pekanbaru \\ Jl. K.H. Ahmad Dahlan No. 96, Sukajadi, Kota Pekanbaru, Riau 28122 \\ Email: alhadijurnal@gmail.com
}

\begin{abstract}
Realities in the community, husbands neglect to educate their wives to become pious wives and mothers, impact the failure of mothers to educate their children and the continuity of happy families, sometimes even ending in divorce. The concept of the husband's responsibility in educating his wife is already in the hadith of the Prophet. The research uses the method of mausu'ah al-Hadis al-Nabawiyah according to the poles of al-Tis'ah. The results of his research, that there are 146 traditions related to the responsibility of the husband in educating his wife. Whereas the material that must be taught by husbands to wives is to teach the science of fardhu in ain (individual obligations) to wives, namely the science of monotheism (the knowledge of the Qur'an and hadith) also called ushuluddin, fiqh (prayer, fasting etc.) and Sufism (moral). Tawheed is taught so that the aqeedah is in accordance with the aqeedah of the sunnah wal jama'ah. The science of jurisprudence is taught so that all worship is in accordance with the will of religion (Shari'a). Sufism is taught so that they are sincere in doing good deeds and can guard all their deeds rather than being damaged by a sense of riya (showing off), proud, pointing at others and others.
\end{abstract}

Keywords: Concept, Husband, Educate, Wife, Hadith

Abstrak: Kenyataan dimasyarakat, para suami lalai mendidik istri agar menjadi istri dan ibu yang shalehah, berdampak kegagalan ibu mendidik anak-anaknya serta kelangsungan keluarga bahagia, bahkan terkadang berakhir pada perceraian. Konsep tanggung jawab suami dalam mendidik istri telah ada dalam hadis Nabi saw. Penelitian menggunakan metode mausu'ah al-Hadis al-Nabawiyah menurut kutub al-Tis'ah. Hasil penelitiannya, bahwa ada 146 hadis yang berkaitan dengan tanggung jawab suami dalam mendidik istri. Sedangkan materi yang wajib diajarkan suami kepada istri adalah mengajarkan ilmu fardhu 'ain (kewajiban individu) kepada isteri yaitu ilmu tauhid (ilmu al-Qur'an dan hadis) disebut juga ushuluddin, fiqih (shalat, puasa dll) dan tasawuf (akhlak). Ilmu tauhid diajarkan supaya aqidahnya sesuai dengan aqidah ahli sunnah wal jama'ah. Ilmu fiqih diajarkan supaya segala ibadahnya sesuai dengan kehendak agama (syariat). Ilmu tasawuf diajarkan supaya mereka ikhlas dalam beramal dan dapat menjaga segala amalannya daripada dirusakkan oleh rasa riya' (pamer), bangga, menunjuk-nunjuk orang lain dan lain-lain.

Kata Kunci: Konsep, Suami, Mendidik, Istri, Hadis 


\section{PENDAHULUAN}

Islam adalah agama yang sempurna mencakup segala aspek kehidupan manusia, hal ini sesuai dengan kitab alQur'an umat Islam yang merupakan kitab penyempurna kitab-kitab terdahulu, juga diwahyukan kepada Nabi saw dan Rasul saw yang paling sempurna. Surah alMaidah ayat 3 menyinggung hal ini:

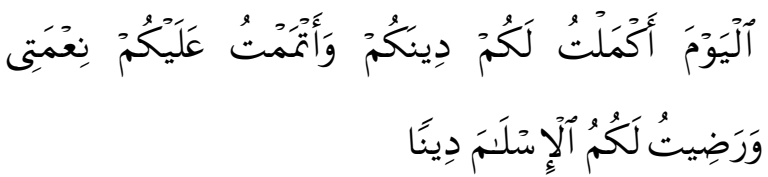

Artinya: Pada hari ini telah KuSempurnakan untuk kamu agamamu, dan telah Ku-cukupkan kepadamu nikmat-Ku, dan telah Ku-ridhai Islam itu jadi agama bagimu (Depag RI, 2015 : 157).

Islam sebagai agama yang paling diridhai Allah swt (surah al-Imran ayat 19), juga menjadi bukti Islam agama yang paling sempurna, dikesempurnaan tersebut Islam juga mengatur bagaimana konsep pendidikan, baik dalam keluarga maupun diluar keluarga. Sederhananya saja yang menjadi dalil bahwa Islam (alQur'an) membawa nilai-nilai pendidikan, terlihat dalam wahyu pertama turun, yaitu surah al-Alaq ayat 1-5 :

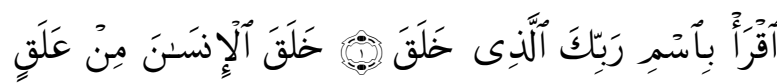

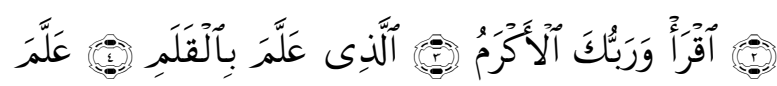

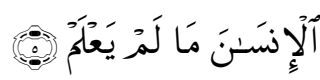

Artinya: Bacalah dengan (menyebut) nama Tuhanmu yang Menciptakan; Dia telah menciptakan manusia dari segumpal darah; Bacalah, dan Tuhanmulah yang Maha pemurah; Yang mengajar (manusia) dengan perantaran kalam (maksudnya: Allah mengajar manusia dengan perantaraan tulis baca); Dia mengajar kepada manusia apa yang tidak diketahuinya (Depag RI, 2015 : 1079)

Ayat di atas mengindikasi pentingnya membaca (belajar), dengan kata lain berkaitan erat dengan pendidikan, yaitu proses belajar mengajar antara malaikat dengan Nabi Muhammad saw. Jika diteliti makna satu persatu lima ayat di atas, bahwa proses pembelajaran adalah pengenalan diri dengan penciptanya, yaitu Allah swt (Hamka, 1982: 11; M. Qurais, 2009: 392). Kemudian sifat lemah manusia (bodoh), dibuktikan dengan ayat ke 4 dan 5 , bahwa Allah swt yang memberikan ilmu tentang tulis baca dan cara memahami alam semesta lewat pengajaran Allah swt dari sesuatu yang tidak tahu menjadi tahu, melalui pengilhaman akal pikiran dan kejernihan hati sanubari (ilmu laduni). Konsep dalam pembelajaran atau kurikulum yang dicontohkan Malaikat Jibril kepada Nabi Muhammad saw adalah kurikulum sima'i bi al-Wa'izhah, hal ini terbentuk dari cara malaikat Jibril menyekap Nabi saw lalu membacakan ayat 1-5 surah al-Alaq diatas (Ibnu Katsir, 1992: 359-360).

Keluarga merupakan unit sosial terkecil yang utama dan pertama bagi seorang istri. Sebelum ia berkenalan dengan dunia sekitarnya, seorang istri akan berkenalan terlebih dahulu dengan situasi keluarga (Mufatihatut, 2015: 110136). Pengalaman pergaulan dalam keluarga akan memberikan pengaruh yang sangat besar untuk kelangsungan kebahagiaan di masa yang akan datang. Sehingga pendidikan yang paling banyak diterima oleh istri seharusnya dalam keluarga (Zakiah Daradjat, 2015: 47).

Keluarga sebagai pendidikan yang pertama dan utama (Ahmad Tafsir, 2011: 155; Armai Arief, 2012: 76). Suami sebagai kepala rumah tangga bertanggung jawab penuh terhadap anggota keluarga, yaitu istri dan anak-anak. Kelalaian mendidik istri agar menjadi istri dan ibu yang shalehah akan berdampak pada kegagalan ibu dalam mendidik anakanaknya dirumah, karena kehidupan anak pada dasarnya tertumpu pada istri sebagai ibunya anak-anak. Namun dikarenakan istri atau ibunya anak-anak juga ikut bekerja mencari penghidupan 
(harta/uang), sehingga tugas ini terabaikan. Tidak jarang kelalaian suami mendidik istri dengan ilmu agama yang baik berakhir pada perceraian. Kelalaian orang tua dalam mendidika anak dengan ilmu agama menjadai phenomena kenakalan remaja yang cukup signifikan (Armai Arief, 2012: 77).

Ayat yang berfokus pada seorang ayah (suami) berkewajiban dan bertanggung jawab mendidik istri, Allah jelaskan dalam al-Qur'an surah al-Tahrim ayat 6 sebagai berikut:

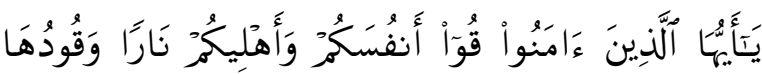

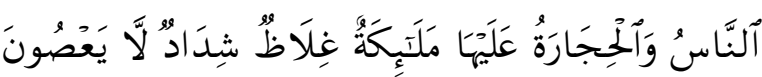

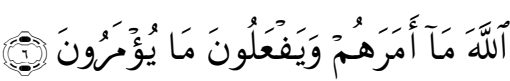

Artinya: Hai orang-orang yang beriman, peliharalah dirimu dan keluargamu dari api neraka yang bahan bakarnya adalah manusia dan batu; penjaganya malaikatmalaikat yang kasar, keras, dan tidak mendurhakai Allah terhadap apa yang diperintahkan-Nya kepada mereka dan selalu mengerjakan apa yang diperintahkan (Depag RI, 2015: 951).

Imam al-Syaukani mengutip perkataan Ibnu Jarir: "Wajib atas kita untuk mengajarkan istri dan anak-anak kita din al-Islam (agama Islam), serta mengajarkan kebaikan dan adab-adab Islam (Abu Ja'far, t.th: 156-157; Ismail bin Katsir, t.th: 412-413; Imam Muhammad bin 'Ali bin Muhammad, t.th: 253). Berkaitan dengan surah Luqman di atas menerangkan bahwa tanggung jawab mendidik anak-anak adalah kewajiban orang tua (A. Samad Usman, t.th: 113). Keluarga yang merupakan lembaga pendidikan yang pertama dan utama tersebut, wajib memberikan pendidikan agama Islam dan menjaga anaknya dari api neraka (Muzayin Arifin, 1991: 7).

Sedangkan hadis tentang suami sebagai kepala rumah tangga untuk mendidik istri diantaranya, sebagaimana dikutip dalam kitab Tafsir Ibnu Katsir, Rasulullah saw bersabda:

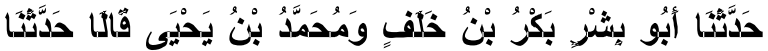

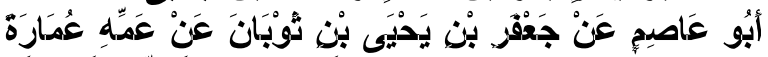

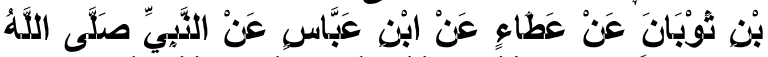

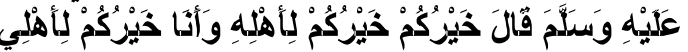
Artinya: Diriwayatkan dari Abu Bisyrinbakr bin Khalaf dan Muhammad bin Yahya, mereka berkata, diceritakan dari Abu 'Ashim dari Ja'far bin Yahya bin Tsauban dari pamannya 'Umarah bin Tsauban dari 'Atha' dari Ibnu Abbas dari Nabi saw, beliau bersabda: Sebaik-baik kalian adalah yang paling baik terhadap keluarganya (istrinya). Dan aku adalah orang yang paling baik di antara kalian terhadap keluargaku (istriku) (HR. Ibnu Majah) (Ibnu Katsir: 477; Imam Ibnu Majah, t.th: 119).

Hadis diatas juga di riwayatkan oleh al-Tirmizi (Imam al-Tirmizi, t.th; 399), alDarimi (Imam Al-Darimi, t.th: 55) dan Ibnu Hibban. Hadits riwayat Tirmidzi dishahihkan oleh al-Albani (Muhammad Nasyiruddin al-Albani, t.th: 285). Sebagaimana Imam al-Syaukani mengatakan diatas, beliau mengutip perkataan Ibnu Jarir.

Melalui ayat dan hadis diatas, agar secara detail hadis-hadis tentang tanggung jawab atau kewajban suami dalam mendidik istri pada kitab hadis kutub al-Tis'ah (shahih bukhari, muslim, abu daud, tirmizi, nasa'i, ibnu majah, ahmad, malik dan darimi)

\section{KERANGKA TEORI}

\section{Teori Tanggung Jawab Kepala Keluarga}

Tanggung jawab suami sebagai kepala keluarga dapat dilihat dalam ayat al-Qur'an surah an-Nisa ayat 34 sebagai berikut:

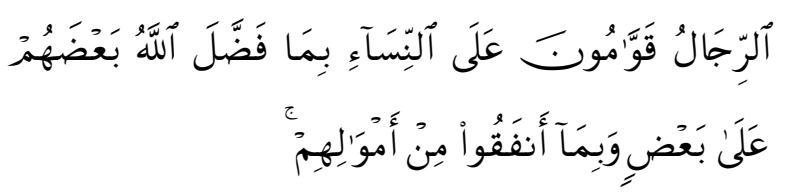

Artinya: Kaum laki-laki itu adalah pemimpin bagi kaum wanita, oleh karena Allah telah melebihkan sebahagian mereka 
(laki-laki) atas sebahagian yang lain (wanita), dan karena mereka (laki-laki) telah menafkahkan sebagian dari harta mereka. sebab itu, maka wanita yang saleh, ialah yang taat kepada Allah lagi memelihara diri (maksudnya: tidak berlaku curang serta memelihara rahasia dan harta suaminya) ketika suaminya tidak ada, oleh karena Allah telah memelihara (mereka) (maksudnya: Allah Telah mewajibkan kepada suami untuk mempergauli isterinya dengan baik). wanita-wanita yang kamu khawatirkan nusyuznya (nusyuz: yaitu meninggalkan kewajiban bersuami isteri. nusyuz dari pihak isteri seperti meninggalkan rumah tanpa izin suaminya), maka nasehatilah mereka dan pisahkanlah mereka di tempat tidur mereka, dan pukullah mereka. Kemudian jika mereka mentaatimu, maka janganlah kamu mencari-cari jalan untuk menyusahkannya (maksudnya: untuk memberi peljaran kepada isteri yang dikhawatirkan pembangkangannya haruslah mula-mula diberi nasehat, bila nasehat tidak bermanfaat barulah dipisahkan dari tempat tidur mereka, bila tidak bermanfaat juga barulah dibolehkan memukul mereka dengan pukulan yang tidak meninggalkan bekas. bila cara pertama Telah ada manfaatnya janganlah dijalankan cara yang lain dan seterusnya). Sesungguhnya Allah Maha Tinggi lagi Maha besar (Depag RI, 2015 : 123).

Menurut ayat di atas sangatlah jelas tanggung jawab laki-laki (suami) sebagai kepala rumah tangga, diantaranya memberikan nafkah kepada keluarga (istri daan anak). Teruntuk kepada istri, jika istri durhaka maka mendidiknya dengan cara menasehatinya, memisahkan tempat tidurnya dan memukulnya dengan pukulan kasih sayang. Secara keseluruhan ayat ini sangat erat kaitanya dengan tanggung jawab mendidik keluarga (istri), tugas in adalah tugas kepala keluarga (suami).

Teori tanggung jawab kepala keluarga dalam mendidik anggota keluarganya secara sederhana dapat di pahami dalam surah at-Tahrim ayat 6 (Depag RI, 2015 : 951). Menurut Quraish Shihab surah al-Tahrim ayat 6 menggambarkan bahwa dakwah dan pendidikan harus bermula dari rumah. Ayat di atas walau secara redaksional tertuju kepada kaum pria (ayah), tetapi ini bukan berarti hanya tertuju kepada pria saja (M. Quraish, 2004: 327). Menurut AlMaraghi yang dimaksud dengan ahlikum dalam ayat 6 surat at-Tahrim ini mencakup istri, anak, hamba sahaya baik laki-laki maupun perempuan. Ahlikum ini wajib mendapatkan pendidikan berupa pemberian ilmu tentang hal-hal yang wajib dikerjakan dalam agama (Ahmad Musthafa, t.th: 162). Sedangkan teori hadis yang menunjukkan tanggung jawab kepala keluarga dalam mendidik anggota keluarganya dapat dilihat dalam hadis beikut ini :

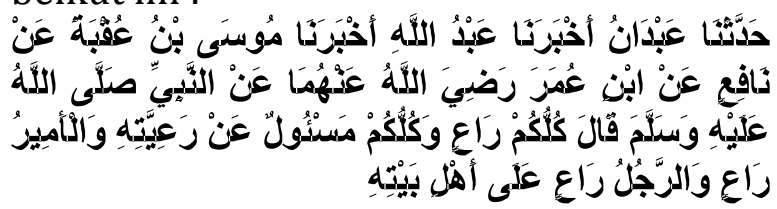

Artinya: Telah menceritakan kepada kami Abdan telah mengabarkan kepada kami Abdullah telah mengabarkan kepada kami Musa bin Uqbah dari Nafi' dari Ibnu Umar R.ahm, dari Nabi saw, beliau bersabda: "Setiap kalian adalah pemimpin. Dan setiap kalian akan dimintai pertanggungjawaban terhadap yang dipimpinnya. Seorang Amir adalah pemimpin. Seorang suami juga pemimpin atas keluarganya. (HR. Bukhari No. 4801, 488, 2232, 2368, 2371, 2546, 4789, 4801, 6605; Muslim No. 3408; Tirmizi No. 1627; Ahmad No. 4266, 4920, 5603, 5635, 5753).

Hadis diatas mengindikasikan tanggung jawab kepala keluarga dalam memimpin dan membimbing (mendidik) anggota keluarga (istri). Didalam hadis lain diluar Kutub al-Tis'ah Rasulullah saw bersabda, yang artinya: "Pertama kali perkara yang dipertanggungjawabkan kepada seseorang di hari kiamat adalah 
keluarganya (yakni isteri) dan anakanaknya. Mereka berkata, wahai Tuhan kami, ambillah hak-hak kami (tanggung jawab) kami dari orang ini, karena sesungguhnya dia tidak mengajarkan kepada kami tentang urusan agama kami. Ia memberi makan kepada kami berupa makanan dari hasil yang haram, dan kami tidak mengetahui. Maka orang itu dihantam (disiksa) lantaran mencari barang yang haram, sehingga terkelupas dagingnya, kemudian dibawa ke neraka". (al-Hadits; Imam Nawawi al-Bantani, 2018). Dalam hadis lain Nabi saw bersabda yang bermaksud: "Takutlah kepada Allah dalam memimpin isteriistrimu, karena sesungguhnya mereka adalah amanah yang berada disampingmu, barangsiapa tidak memerintahkan shalat kepada isterinya dan tidak mengajarkan agama kepadanya, maka ia telah berkhianat kepada Allah dan Rasul-Nya." (al-Hadits; Imam Nawawi al-Bantani, 2018).

\section{METODOLOGI}

Jenis penelitian ini adalah termasuk penelitian kualitatif, karena sifat data yang akan dikumpulkan bercorak kualitatif (Lexy J Moleong, 2001: 11; Imam Suprayogo, 2002: 9; Bungin Burhan, 2004: bersifat naturalis dengan memakai logika induktif dan pelaporannya bersifat deskriptif (Hadari Nawawi, 2009: 67; Dedy Mulyana, 2005: 27). Penelitian ini terfokus pada penelitian kepustakaan (library research) atau studi teks (Iskandar, 2010: 29; HB Sutopo, 2004: 17). Maka penelitian ini akan lebih memusatkan perhatian pada pengkajianpengkajian terhadap teks, dan termasuk jenis penelitian kualitatif (Hamidi, 2004: 13; Neong Muhajir, 1998: 17). Penelitian kepustakaan dilakukan karena sumbersumber datanya, baik yang utama (primary resources) maupun pendukung (secondary resources) seluruhnya adalah teks (Muhammad Nazir, 1997: 58; Sugiyono, 2006: 21).

\section{PEMBAHASAN}

Penelitian ini dilakukan oleh penulis dalam kitab mausu'ah al-hadis alNabawiyah, dari persepktif kitab hadis kutub al-Tis'ah. Maka dapat ditemukan hadis berkaitan dengan tanggung jawab atau kewajiban mendidik istri sebanyak 146 hadis dalam kitab tersebut, dimulai dari hadis shahih Bukhari sampai alDarimi. Lihat tabel mausu'ahnya sebagai berikut:

31). Oleh karena itu data penelitian

\begin{tabular}{|c|c|c|c|}
\hline No & Riwayat Hadis (Mukharij) & Jumlah Hadis & Nomor Hadis \\
\hline 1 & Bukhari & 40 & $\begin{array}{l}65,95,102,488,595,1623,1625,1626, \\
1777,1778,2144,2232,2358,2361, \\
2368,2371,2546,2789,3190,4054, \\
4642,4693,4697,4731,4740,4789, \\
4801,4802,4803,4880,4945,4951, \\
5124,5583,6190,6551,6605,6644, \\
6705,6893\end{array}$ \\
\hline 2 & Muslim & 11 & $\begin{array}{l}499,503,503,1080,1815,1816,2019, \\
2554,3180,3233,3408\end{array}$ \\
\hline 3 & Abu Daud & 11 & $\begin{array}{l}246,249,1113,1238,1239,1450,1628, \\
1806,2152,2539,3065\end{array}$ \\
\hline 4 & Tirmizi & 7 & $\begin{array}{l}1032,1083,1387,1561,1627,1989, \\
3012\end{array}$ \\
\hline 5 & Nasa'i & 11 & $\begin{array}{l}203,205,631,1592,1610,2109,3095, \\
3292,3402,3522,5325\end{array}$ \\
\hline 6 & Ibnu Majah & 10 & $\begin{array}{l}618,1325,1326,1841,1946,2284, \\
2801,3046,3849,4020\end{array}$ \\
\hline
\end{tabular}




\begin{tabular}{|c|c|c|c|}
\hline 7 & Ahmad & 46 & 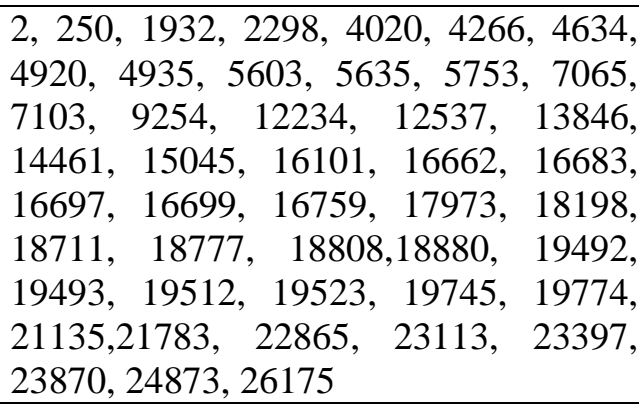 \\
\hline 8 & Malik & 1 & 968 \\
\hline 9 & Al-Darimi & 9 & $\begin{array}{l}290,761,775,1225,1836,2146,2159, \\
2298,3256\end{array}$ \\
\hline \multicolumn{2}{|r|}{ Jumlah Hadis } & \multicolumn{2}{|r|}{146} \\
\hline
\end{tabular}

Diantara 146 hadis peneliti membuat mengambil beberapa hadis saja, misalnya hadis riwayat imam Bukahari No. 595 pada Kitab: Adzan, Bab: Adzan dan iqamah bagi musafir bila shalat berjama'ah begitu juga di 'Arafah dan Mudzdalifah, No. Hadist: 595, hadisnya sebagai berikut:

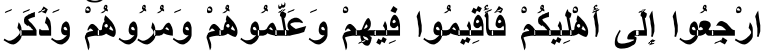

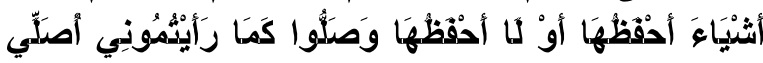

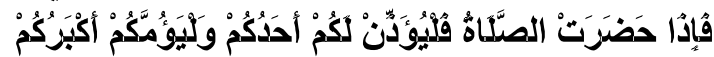

Artinya: "Kembalilah kepada keluarga kalian dan tinggallah bersama mereka, ajarilah mereka dan perintahkan (untuk shalat)." Beliau lantas menyebutkan sesuatu yang aku pernah ingat lalu lupa. Beliau mengatakan: "Shalatlah kalian seperti kalian melihat aku shalat. Maka jika waktu shalat sudah tiba, hendaklah salah seorang dari kalian mengumandangkan adzan, dan hendaklah yang menjadi Imam adalah yang paling tua di antara kalian (HR. Bukhari No. 595, 6705, Muslim No. 1080; Al-Nasa'i No. 631, Ahmad No. 15045, Al-Darimi No. 1225).

Hadis diatas menunjukkan betapa pentingnya keluarga, sehingga tidak dibenarkan meningalkan keluarga dalam waktu yang cukup lama, dikarenakan anggota keluarga memerlukan bimbingan dan pendidikan dari kepala keluarga, hadis diatas juga mengindikasikan betapa besarnya tanggung jawab kepala keluarga (suami) dalam mendidik anggota keluarganya terutama istri (Ahmad bin Ali bin Muhammad, $1418 \mathrm{H} / 1997 \mathrm{M}$; terj. Amiruddin, 2009: 231). Senada dengan hadis diatas, yang berkaitan dengan kewajiban mendidik keluarga bagi kepala rumah tangga atau keluarga (suami). Jika suami tidak melaksanakan kewajiban tersebut menanggung dosa besar dan dikatakan penghianat amanah Allah swt. Nabi saw bersabda yang bermaksud: "Tidak ada seseorang yang menjumpai Allah swt dengan membawa dosa yang lebih besar daripada seorang suami yang tidak sanggup mendidik keluarganya." (alHadits; Imam Nawawi al-Bantani, 2018).

Berikutnya misalnya hadis riwayat al-Darimi No. 3256 ada pada Kitab: Kitab keutamaan alquran, Bab: Keutamaan surat Albaqarah dan ayat kursi, No. Hadist: 3256, hadis sebagai berikut:

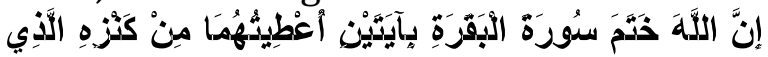

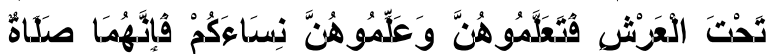

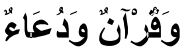

Artinya: "Sesungguhnya Allah menutup surat AlBaqarah dengan dua ayat yang diberikan kepadaku dari perbendaharaan-Nya yang berada di bawah 'Arys, maka pelajarilah dan ajarkanlah kedua ayat itu kepada isteri-isteri kalian, sebab keduanya adalah shalat, Al-Qur'an dan doa (HR. Al-Darimi No. 3256) (Abdurrahman ibn 'Abdirahman, t.th: 3256).

Hadis diatas dapat menjadi dalil pentingnya mengajarkan al-Qur'an terutama surah al-Baqarah kepada istri, karena dalam surah tersebut mengandung 
banyak pelajaran yang dapat diterapakan dalam ruamah tangga, terutama sebagai seorang istri. Ujung hadis tersebut menyebutkan bahwa al-Qur'an itu apabila dibaca dan dipelajari akan menjadi doa dan perbendaharaan dunia akhirat. Adapun dua ayat di akhir surah alBaqarah adalah ayat ke 285-286 (Abu Muhammad Abdulloh bin Abdurrohman Ad-Daromi, 2000; al-Darimi, 1424 H/2013 M ; al-Darimi, 1419 H/1999 M ; al-Darimi, terj. Abdul Syukur Abdul Rozaq Ahmad Riva'i Usman, 2006: 285). Yang isinya syarat mengandung nilai-nilai Tauhid dan Tasawuf dan Do'a (QS (2) ayat 285-286).

Selanjutnya hadis riwayat imam Bukhari No. 95 ada pada Kitab: Ilmu, Bab: Mengajarkan ilmu kepada hamba sahaya dan keluarganya, No. Hadist: 95, hadisnya sebagai berikut:

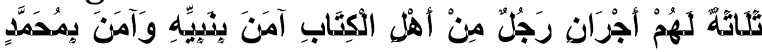

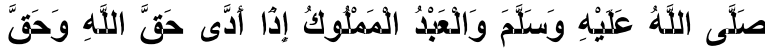

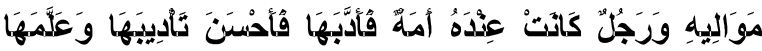

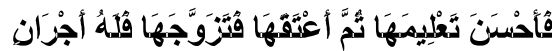

Artinya: "Ada tiga orang yang akan mendapat pahala dua kali; seseorang dari Ahlul Kitab yang beriman kepada Nabinya dan beriman kepada Muhammad shallallahu 'alaihi wasallam, dan seorang hamba sahaya yang menunaikan hak Allah dan hak tuannya. Dan seseorang yang memiliki hamba sahaya wanita lalu dia memperlakukannya dengan baik, mendidiknya dengan baik, dan mengajarkan kepadanya dengan sebaikbaik pengajaran, kemudian membebaskannya dan menikahinya, maka baginya dua pahala". (HR. Bukhari No. 95, 2358, 2361, 2789, 3190, 4693, Muslim No. 2019; Nasa'i No. 3292; Ibnu Majah No. 1946; Ahmad No. 18880, 18711, 18777, 18808, Al-Darimi No. 2146) (Abu Abdillah Muhammad al-Bukhari, t.th: No. 95).

Menurut peneliti, isi hadis-hadis diatas tersebut mengindikasikan kewajiban Suami mengajar dan mendidik Istri dengan di istilahkan seorang budak, karena seorang Istri wajib ta'at dan patuh kepada suami seolah-olah seperti budak yang wajib ta'at dan patuh terhadap majikannya (Ahmad bin Ali bin Muhammad Al-Asqalani Al-Mishri, 1418 H/1997 M ; Al-Asqalani Al-Mishri, , terj. Amiruddin, 2009 : 493). Seorang Majikan (tuan) yang baik kepada hamba (budak) nya, misalnya dengan budak perempuan, maka dia akan mendidik dan mengajarkan (agama) sehingga menjadi hamba sahaya (budak) yang shalehah, lalu majikanya menikahinya, maka majikan tersebut mendapat dua pahala (Ahmad bin Muhammad Al-Sindi Al-Madani, t.th ; Abdurrahman bin Kamaluddin Jalaluddin al-Misri as-Suyuthi asy-Syafi'i al-Asy'ari, t.th; Ahmad bin Syu'aib bin Ali, terj. Ahmad Yoswaji, 2004: 387). Demikian halnya seoarang Suami yang mendidik dan mengajarkan Istri ilmu agama, maka ia akan mendapatkan dua pahala (Alauddin al-Mughlathi, t.th ; Abdurrahman bin Kamaluddin Jalaluddin al-Misri as-Suyuthi asy-Syafi'i al-Asy'ari, t.th ; Abul Hasan bin Abdul Hadi As-Sindi, t.th; Abdul Ghoni Ad-Dahlawi, t.th; AlFakhru al-Hasan Al-Katskawi, t.th; AnNu'mani, t.th; Abu Abdullah Muhammad bin Yazid Al-Qazwini, terj. Iqbal dan Mukhlis, 2005: 677). Sebagaimana dalam hadis sebelumnya Rasul saw mengatakan bahwa istri itu adalah tawanan, perlakukanlah dengan baik istri tersebut, yaitu dengan mengajarkan akhlak (adab) yang baik, juga mengajarkan ilmu agama dengan baik kepada istri, maka tanggung jawab seperti ini akan Allah swt ganjar dengan dua pahala, inilah untunngya jika menikahi wanita yang kurang ilmu agamanya, maka suami berkewajiban mendidik dan mengajarkan ilmu agama, sehingga suami seperti ini mendapat kemulian, bukan hanya sebagai suami yang harus ditaati namun juga sebagai guru yang harus dimuliakan (Abul Hasan bin Abdul Hadi As-Sindi, 1428 H/2008M ; Ahmad Muhammad Syakir dan Ahmad alZain, t.n.pentrj, 2009; Ahmad bin Muhammad bin Hanbal, terj. Muhammad Iqbal, 2007: 199). Suami seperti ini akan 
mendapatkan pahala dua kali lipat (Abu Muhammad Abdulloh Ad-Daromi, 2000; al-Darimi, $1424 \mathrm{H} / 2013 \mathrm{M}$; al-Darimi, 1419 H/1999 M; al-Darimi, terj. Abdul Syukur Abdul Rozaq Ahmad Riva'i Usman, $2006: 563)$.

Kemudian Hadis riwayat imam Nasa'i No. 1592 ada pada Kitab: Qiyamul lail dan shalat sunnah siang hari, Bab: Motivasi shalat malam, No. Hadist: 1592, hadisnya sebagai berikut:

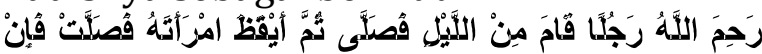

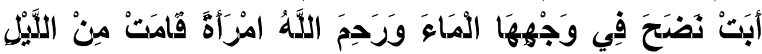

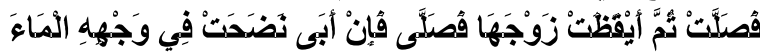
Artinya: "Allah merahmati seorang pemuda yang bangun untuk shalat dimalam hari, lalu ia membangunkan istrinya untuk shalat, jika ia enggan maka ia memercikkan air diwajahnya, dan Allah merahmati seorang istri yang bangun untuk shalat dimalam hari lalu ia membangunkan suaminya untuk shalat, jika ia enggan maka ia memercikkan air kewajahnya. (HR. Nasa'i No. 1592; Abu Daud No. 1113, 1239, 1238; Ibnu Majah No. 1325, 1326 dan Ahmad No. 7103, 9254, 7065) (Abu 'Abdirrahman ahmad bin su'aib bin ali bin bahr bin sinan bin dinar an-Nasai al-Kurasani, t.th: hadis No. 1592).

Hadis diatas memberikan gambaran kewajiban dan tanggung jawab suami dalam mendidik istri agar menjadi istri yang shalehah, yaitu taat kepada Allah swt, sebagaimana hadis diatas memberikan sinyal bahwa suami wajib mengajak istri untuk shalat Tahajjud, jika istri enggan untuk bangun shalat Tahajjud, maka kewajiban mendidiknya dengan cara yang santun dan kasih saying, yaitu memercikkan air kewajahnya, ini tanggung jawab suami mendidik istri agar rajin bangun malam dan shalat malam. Namun hadis diatas tidak hanya kepada suami, begitu juga istri punya tanggung jawab yang sama kepada suaminya untuk mengajak shalta malam suaminya, kalau suami taat kepada Allah swt insyaallah keluarga akan bahagia (Ahmad bin
Muhammad Hayat Al-Sindi Al-Madani, t.th; Jalaluddin al-Misri as-Suyuthi asySyafi'i al-Asy'ari, t.th ; Ahmad bin Syu'aib bin dinar, terj. Ahmad Yoswaji, 2004: 651).

\section{PENUTUP}

Konsep Tanggung Jawab Suami Mendidik Istri Menurut Hadis Nabi Muhammad saw dalam Kutub Al-Tis'ah dapat disimpulkan sebagai berikut :

1. Kewajiban suami menjadi pemimpin bagi isteri dalam rumah tangga dan keluarga dengan cara mengayominya dan memberikan pendidikan kepada anggota keluarga (istri).

2. Kewajiban mengajarkan ilmu fardhu 'ain (kewajiban individu) kepada isteri yaitu ilmu tauhid (ilmu al-Qur'an dan hadis) disebut juga ushuluddin, fiqih (shalat, puasa dll) dan tasawuf (akhlak). Ilmu tauhid diajarkan supaya aqidahnya sesuai dengan aqidah ahli sunnah wal jama'ah. Ilmu fiqih diajarkan supaya segala ibadahnya sesuai dengan kehendak agama (syariat). Ilmu tasawuf diajarkan supaya mereka ikhlas dalam beramal dan dapat menjaga segala amalannya daripada dirusakkan oleh rasa riya' (pamer), bangga, menunjuk-nunjuk orang lain dan lain-lain.

3. Kewajiban menghindari perbuatan zalim kepada istri dalam mendidiknya yaitu dengan cara: 1). Memberikan pendidikan agama yang sempurna, jika ilmu agama istri tidak lengkap, maka hal ini termasuk zalim suami kepada keluarga. 2). Memberikan nafkah lahir dan batin secukupnya. 3). Memberi nasihat serta menegur dan memberi panduan/petunjuk jika melakukan maksiat atau kesalahan. 4). Apabila memukul jangan sampai melukai (melampaui batas).[] 


\section{DAFTAR RUJUKAN}

Abdillah, Abu Muhammad bin Isma'il bin Ibrahim bin al-Mughirah bin Bardizbah al-Ju'fi Al-Bukhari. AlJamiu al-Shahih al-Bukhari, Beirut: Dar al-Fikri, t.th.

Abdillah, Abu Muhammad bin Ismail AlBukhari bin Ibrahim bin AlMughirah bin Bardizbah, Imam alBukhari. Sahih Bukhari, Bairut: Darul Ibnu Katsir al-Yammah, t.th.

Abdillah, Abu Muhammad bin Yazid bin 'Abdillah bin Majah Al-Qazwini. AlSunan Ibnu Majah, Mesir: Maktabah al-Sunnah, t.th.

Abdirrahman, Abu Ahmad bin su'aib bin ali bin Bahr bin Sinan bin Dinar alKurasani Al-Nasai. Al-Sunan alNasa'I, Cairo: Dar Ilmi, t.th.

Abdullah, Abu Muhammad bin Yazid ArRabi' bin Majah Al-Qazwini. Sunan Ibnu Majah, terj. Iqbal dan Mukhlis, Jakarta: Pustaka Azam, 2005.

Abdullah, bin Abdurrahman bin al Fadhl bin Bahram bin Abdush Shamad AlDarimi. Sunan Al-Darimi/Musnad AlDarimi, terj. Abdul Syukur Abdul Rozaq Ahmad Riva'i Usman, Jakarta: Pustaka Azam, 2006.

Abdurrahman, bin Kamaluddin Abu Bakr bin Muhammad bin Sabiquddin, Jalaluddin al-Misri al-Syafi'i alAsy'ari Al-Suyuthi. Sunan al-Nasa'i bi Syarhi al-Suyuthi, Beirut: Dar alMa'rifah, t.th.

Abdurrahman, ibn 'Abdirahman ibn alFadhl ibn Bahram ibn 'Abdis Shamad Al-Darimi. Al-Sunan Al-Darimi, Kairo Mesir: Maktabah alamiyah, t.th.

Agama, Departemen RI, Al-Qur'an dan Terjemahanya, Semarang: Toha Putra, 2015.

Ahmad, bin Ali bin Muhammad bin Muhammad bin Ali bin Mahmud bin Ahmad bin Hajar Al-Kannani AlMishri Al-Asqalani. Fath al-Barri fi Syarhi al-Bukhari, Riyadh: Maktabah Darussalam, 1997.
Ahmad, bin Muhammad bin Hanbal AlSyaibani, Musnad Ahmad, terj. Muhammad Iqbal, Jakarta: Pustaka Azam, 2007.

Ahmad, bin Muhammad Hayat bin Ibrahim Al-Sindi Al-Madani. Zahra al-Ruba' 'ala al-Mujtaba' fi Syarhi al-Sunan alNasa'i, Lebanon: Dar al-Sunnah, t.th.

Ahmad, bin Muhammad ibn Hanbal AlSyaibani. Al-Musnad Ibnu al-Hambali, Lebanon: Dar al-Hadis, t.th.

Ahmad, bin Syu'aib bin Ali bin Sofyan bin Bahr bin dinar. Sunan Nasa'i, terj. Ahmad Yoswaji, Jakarta: Pustaka Azam, 2014.

al-Hasan, Al-Fakhru Al-Katskawi. $\quad M a$ Yaliqu Min Halli al-Lughot fi Syarhi Sunan Ibnu Majah, Dar al-Afkar alDauliyah, t.th.

Al-Jaziri, Abdurrahman. kitab al-fiqh 'ala al-Mazahib al-Arba'ah, Beirut: dar alFikr, 1972.

Al-Mughlathi, Alauddin. Al-I'lam bi Sunnati Syarhi sunan Ibnu Majah, Beirit: Dar Kutub Ilmiyah, t.th.

Al-Nu'mani. Mukhtashor Ma Tamassu Ilaihi al-Hajah fi Syarhi Sunan Ibnu Majah, Dar al-Afkar al-Dauliyah, t.th.

Arief, Armai. Pengantar Ilmu dan Metodologi Pendidikan Islam, Jakarta: Ciputat Pers, 2012.

Arifin, Muzayin. Pendidikan Islam dalam Arus Dinamika Masyarakat, Jakarta: PT. Golden Terayon, 2011.

Burhan, Bungin. Metodologi Penelitian Kualitatif, Jakarta: Raja Grafindo Persada, 2014.

Daradjat, Zakiah. Pendidikan Islam dalam Keluarga dan Sekolah, Jakarta: CV. Ruhama, 2015.

Ghoni, Abdul Ad-Dahlawi. Injahul Hajah fi Syarhi Sunan Ibnu Majah, Dar alAfkar al-Dauliyah, t.th.

Hadi, Abu Sura'i Abdul. Bunga Bank Dalam Islam, alih bahasa M. Thalib, Surabaya: al-Ikhlas 2013.

Hamidi. Metode penelitian kualitatif, Malang: Universitas Muhammadiyah Malang, 2014. 
Hamka. Tafsir Al-Azhar, Jakarta: Pustaka Panji Mas, 2012.

Hasan, Abul bin Abdul Hadi Al-Sindi. Hasyiah Musnad al-Imam Ahmad Ibnu Hambal, Lebanon Beirut/Syuria Dimisq: Dar al-Nawadir, 2008.

Hasan, Abul bin Abdul Hadi Al-Sindi, Kifayatul Hajah fi Syarhi Sunan Ibnu Majah, Dar al-Afkar al-Dauliyah, t.th.

Husain, Abul Muslim bin al-Hajjaj AlNaisaburi Imam Muslim. Shahih Muslim, Beirut: Dar Ibnu Katsir, t.th.

Majah, Ibnu Imam. Sunan Ibnu Majah, Lebanon: Dar al-Sunnah, tt.

Imam, Al-Darimi. Sunan al-Darimi, Lebanon: Dar al-Sunnah, t.th.

Al-Tirmizi, Imam. Sunan Al-Tirmizi, Lebanon: Dar al-Sunnah, t.th.

Isa, Abu muhammad bin 'Isa bin Surrah alTurmudzi Ibn Musa Ibn Adh-Dhahak Al-Sulami Al-Bughi Al-Tirmidzi. AlSunan Al-Tirmizi, Lebanon: Dar alHadis, t.th.

Iskandar. Metode Penelitian Kualitatif: Aplikasi untuk Penelitian Pendidikan, Hukum, Ekonomi \& Manajemen, Sosial, Humaniora, Politik, Agama dan Filsafat, Jakarta: Gaung Persada, 2010.

Al-Thabari, Ibnu Jarir. Tafsîr al-Thabâri, Cairo: Darul Kutub Ilmiyah, t.th.

Katsir, Ibnu. Tafsir Ibnu Katsir, Surabaya: PT. Bina Ilmu, 2012.

Katsir, Ismail bin. Tafsiir Ibnu Katsir, Lebanon: Maktabah Darus Salam, tt.

Malik, Abdullah ibn Anas ibn Malik ibn Abi Amir ibn Amr ibn al-Haris ibn Gaiman ibn Husail ibn Amr ibn alHaris al-Asbahi Al-Madani. AlMua'tha' Imam Malik, Beirut: Dar Fikri, t.th.

Moleong, Lexy J. Metodologi Penelitian Kualitatif, Bandung: Remaja Rosdakarya, 2011.

Muhajir, Neong. Metodologi Penelitian Kualitatif, Yogyakarta: Rake Sarasin, 2010.

Muhammad, Abi Abdillah bin Abdirrahman bin Fahdil al-Darimi.
Fathu al-Manan Syarhi wa al-Tahqiqi Musnad al-Jami' al-Darimi, Beirut: Dar al-Basyair al-Islamiyah/Makkah: al-Maktabah al-Makkiyah, 1999.

Muhammad, Abu Abdulloh bin Abdurrohman Muhammad. Musnad Al-Daromi/al-Darimi (Sunan AlDaromi), Riyadh: Darul Mughni, Saudi, 2000.

Muhammad, bin 'Ali bin Muhammad bin 'Abdullah al-Syawkani al-Qadli AlShan'ani, Tafsîr Fath al-Qadîr, Beirut: Darul Fikr, t.th.

Mulyana, Dedy. Metodologi Penelitian Kualitatif, Bandung: Remaja Rosdakarya, 2015.

Musthafa, Ahmad Al-Maraghi. Tafsir alMaraghi, Mesir, al-Babi Halabi, t.th.

Nasyiruddin, Muhammad Al-Albani. Shahih Sunan Al-Tirmizi, Riyadh: Maktabah ilmiyah, t.th.

Nawawi, Hadari. Metode Penelitian Bidang Sosial, Yogyakarta: Gajah Mada University Press, 2010.

Nazir, Muhammad. Metodologi Penelitian, Jakata: Ghalia Indonesia, 2011.

Shalahuddin, Agus dan Agus Suyadi. Ulumul Hadits, Bandung: Pustaka Setia, 2008.

Shihab, M. Quraish. Tafsir Al-Misbah (Pesan, Kesan dan Keserasian alQur'an), Jakarta; Lentera Hati, 2010.

Suprayogo, Imam dan Tobroni. Metodologi Penelitian Sosial-Agama, Bandung: Remaja Rosdakarya, 2012.

Sutopo, HB. Pengantar Penelitian Kualitatif, Surakarta: Universitas Sebelas Maret Press, 2014.

Syakir, Ahmad Muhammad dan Ahmad alZain. Syarhi al-Musnad al-Imam Ahmad, terj, Jakarta: Pustaka Azam, 2009.

Tafsir, Ahmad. Ilmu Pendidikan dalam Perspektif Islam, Bandung: Remaja Rosda Karya, 2011.

Taubah, Mufatihatut. "Pendidikan Anak dalam Keluarga Perspektif Islam". Jurnal Pendidikan Agama Islam 3.1 (2015). 